\title{
THE USE OF WIRE STRAIN GAGES TO DETECT SOME TYPES OF SPLITTING FAILURE IN NOTCHED COMPOSITES
}

By

\author{
Hatem H. DAKEN ${ }^{1}$
}

\begin{abstract}
Two experimental investigations have demonstrated the extreme usefulness of using wire strain gages in studying the mechanical behavior of composites. Wire strain gages have also shown their capacity in detecting some splitting failure types in notched composites under tensile loads.

The first investigation entailed notched $\left[0^{\circ}\right]_{8}$ unidirectional graphite/epoxy composites. An arrangement of wire strain gages around the notch boundary has easily detected the onset of splitting damage in the specimen. Splitting damage is through-the-thickness matrix cracks emanating from the notch tips and propagating along the filament direction. The second investigation entailed notched $\left[0 / \pm 45^{\circ}\right]_{s}$ graphite/epoxy laminates. Splitting damage in both the $0^{\circ}$ and $45^{\circ}$ plies have been identified using a modified gage arrangement.
\end{abstract}

\section{INTRODUCTION}

Composite materials exhibit a multitude of complex damage mechanisms. Damage in brittle metals is mainly in the form of a self-symmetric crack normally propagating to the direction of maximum stress in the specimen. Matrix crazing, fiber fracture, fiber crippling, matrix splitting, and delamination are but a few of the many damage mechanisms that has been identified in advanced composites. The various micro structural mechanisms of damage accumulation in composites occur sometimes independently and sometimes interactively. The predominance of one or another of these mechanisms may be affected by material variables and loading conditions. The process of damage accumulation depends on the relative strength and stiffness of the filament/matrix combination, the nature of the interfacial bond, and the manner in which the fibers are distributed in the composite. Damage paths are highly complex and all the micro structural and macroscopic failure processes may contribute, to different degrees, to degrade the mechanical properties of the composite. Also, the nature of the interaction between the different damage mechanisms, present at any instant during loading, can largely change the damage propagation paths, or even create new paths.

1 Assist Professor of Mechanical Design and Head, Design with Innovative Materials Group. Military Technical College, Cairo, EGYPT. 
In making more efficient use of composites, it is important to understand fully their failure modes and fracture characteristics.

Several researchers have investigated the capacity of using wire strain gages in detecting some of the damage mechanisms in composites. Daniel et al [1] used an embedded strain gage technique to establish a relationship between surface and subsurface strains to failure in boron/epoxy tension coupons of three different lay-ups. It would then be possible to calculate the critical subsurface strains up-to-failure by measuring surface strains only. In a land mark investigation, Daniel [2] also used a strain gage arrangement on the hole boundary of notched boron/epoxy specimens to measure deformation to failure. Pipes [3] investigated the reduction in mechanical properties due to cyclic growth of the interlaminar damage, caused by shear stresses, with the aid of wire strain gages. A strain gage arrangement had also been employed by Bhatia [4] to detect the arrestment of cracks in buffer strips and prove the potential of this concept. Strain gages had also been placed on the curved surface of a hole, in a study by Strands [5], to detect interlaminar strains and delamination damage, at the hole surface, in notched thick graphite/epoxy laminates. Daniel [6] also used an elaborate strain gage arrangement to study damage initiation and propagation in slit notched graphite/epoxy plates under biaxial tensile loading, as also to determine the influence of slit length on failure. The slits in this study were oriented to obtain a shear stress component that is larger than the normal component. Initial crack extension and sub-cracks, parallel to the fibers of various plies, had been identified. Lagace detected $90^{\circ}$ ply splitting using an arrangement consisting of a single gage [7].

The objective of this paper is to show how two different strain gage arrangements have been successfully employed to detect two types of splitting in two different laminates.

\section{TEST SPECIMENS}

The test specimen geometry used in the two investigations is the one developed by TELAC (Technology Laboratory for Advanced Composites, MIT). This specimen is a flat one and nominally $350 \mathrm{~mm}$ in length and $50 \mathrm{~mm}$ in width. Loading tabs, $75 \mathrm{~mm}$ in length and beveled to $30^{\circ}$ at one end, are bonded to both faces of the specimen ends using film adhesive. This specimen geometry is an adaptation of the standard ASTM specimen for composite materials [8]. All the specimens were notched with through-the-thickness circular holes of three nominal diameters: $3.175 \mathrm{~mm}\left(1 / 8^{\prime \prime}\right), 6.350 \mathrm{~mm}\left(1 / 4^{\prime \prime)}\right.$, and $9.525 \mathrm{~mm}\left(3 / 8^{\prime \prime}\right)$. In addition to these sizes, specimens of the $\left[0 / \pm 45^{\circ}\right]_{\mathrm{s}}$ lay-up had $12.70 \mathrm{~mm}\left(1 / 2^{\prime \prime}\right)$ holes. The smallest of the corresponding width-to-notch ratio was large enough to minimize finite width effects in the net section [8].

Hercules AS!/3501-6 graphite/epoxy prepreg was used to lay-up 300x350 mm plates with the two above lamination sequences. A standard temperature cycle with one-hour hold at $116^{\circ} \mathrm{C}\left(240^{\circ} \mathrm{F}\right)$ and two-hour hold at $177^{\circ} \mathrm{C}\left(350^{\circ} \mathrm{F}\right)$ was used to cure these plates. Autoclave pressure and bag vacuum were maintained throughout the cure cycle at $0.58 \mathrm{MPa}$ (86 psi) and $740 \mathrm{~mm}$ mercury, respectively. This was followed by an eight-hour post cure 
at $177^{\circ} \mathrm{C}\left(350^{\circ} \mathrm{F}\right)$. Specimens were cut on a milling machine using water-cooled diamond wheels and were then randomly ordered. Holes were drilled using a standard drilling machine and diamond-coated drill/reamer sets.

Minnesota Mining and Materials 3M SP 1003 unidirectional glass/epoxy prepreg was used to manufacture $300 \times 600 \mathrm{~mm}[0 / 90] 2 \mathrm{~s}$ plates. The glass/epoxy cure cycle consisted of twohour temperature hold at $166^{\circ} \mathrm{C}\left(330^{\circ} \mathrm{F}\right)$ with $0.41 \mathrm{MPa}(60 \mathrm{psi})$ autoclave pressure and $740 \mathrm{~mm} \mathrm{Hg}$ vacuum on the plate. Loading tabs, $75 \times 50 \mathrm{~mm}$, were then cut from these plates and beveled on one of their shorter ends. American Cyanamid's FM-132-2 film adhesive was used to bond the loading tabs to the specimens' ends. Bonding involved a onehour hold at $107^{\circ} \mathrm{C}\left(225^{\circ} \mathrm{F}\right)$ under $0.07 \mathrm{MPa}(10 \mathrm{psi})$ autoclave pressure and $740 \mathrm{~mm} \mathrm{Hg}$ vacuum on the specimen.

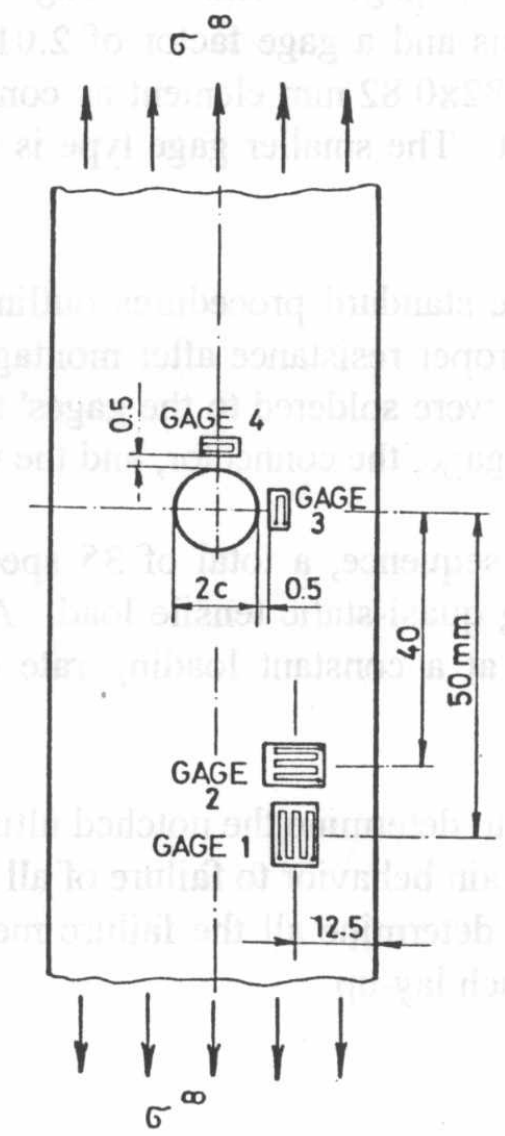

(A)

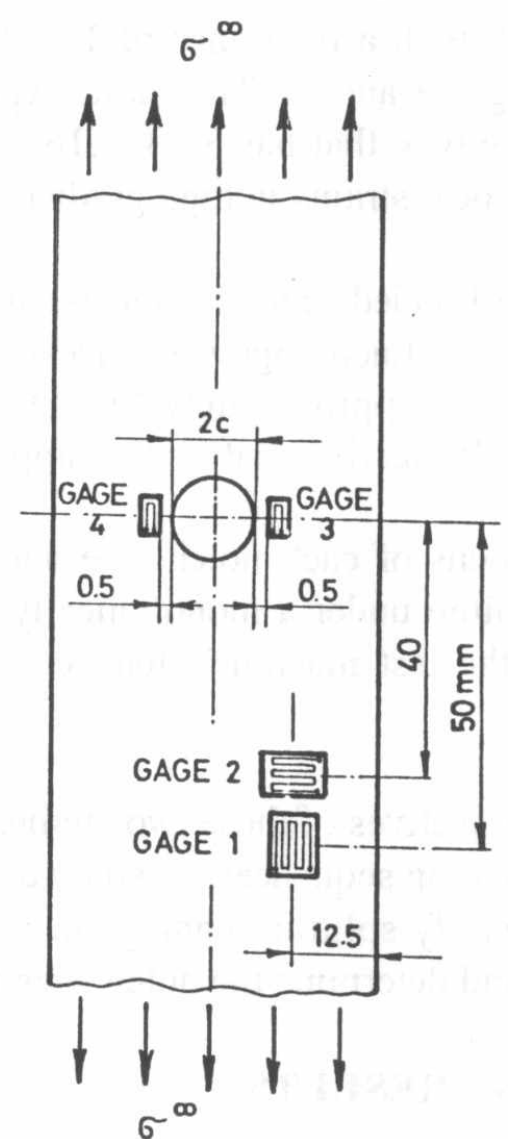

(B) 


\section{TEST PROCEDURE}

All the specimens tested were instrumented with four wire strain gages. Two strain gage arrangements were used in the investigation, Figure (1). Gage arrangement (A) was used for the $\left[0^{\circ}\right] 8$ specimens while arrangement $(B)$ was used for the $\left[0 / \pm 45^{\circ}\right]_{\text {s }}$ specimens. Gages 1 and 2 were used to measure the longitudinal and transverse far-field strains, respectively. In gage arrangement $(A)$, gage 3 was used to measure the longitudinal strain at the right notch tip while gage 4 was used to measure the transverse strain at the upper notch tip. The only difference in arrangement (B) was that both gages 3 and 4 were used to measure longitudinal strains at the right and lef notch tips. With gage arrangement (A), only the splitting at the right hole tip could be detected. With arrangement (B), on the other hand, splitting at both hole tips could be detected.

Micro measurements' gage type EA-06-125AD-120, with a resistance of $120 \pm 0.15 \%$ ohms and gage factor of $2.04 \pm 0.5 \%$, was used for both gages 1 and 2 . Gage type EA-06$031 \mathrm{DE}-120$, with a resistance of $120 \pm 0.2 \% \mathrm{ohms}$ and a gage factor of $2.01 \pm 1.0 \%$ was used for gages 3 and 4 . The Latter type has a $0.82 \times 0.82 \mathrm{~mm}$ element as compared to the $125 \mathrm{AD}$ gage type that has $3.18 \times 3.18 \mathrm{~mm}$ element. The smaller gage type is therefor used to measure local strains in high gradient fields.

Gages were bonded onto the specimens using the standard procedures outlined by Micro measurements. Each gage was checked for the proper resistance after montage. Insulated electrical wires, approximately $450 \mathrm{~mm}$ in length, were soldered to the gages' terminals and connectors. Protective coating was applied to the gage, the connector, and the wire lead.

Five specimens of each notch size and stacking sequence, a total of 35 specimens, were tested to failure under a monotonically increasing quasi-static tensile load. All tests were run under the test machine's load control mode at a constant loading rate of $222 \mathrm{~N} / \mathrm{sec}$ (20 lbs/sec).

The main objectives of these two studies were: 1 - to determine the notched ultimate strength for both stacking sequences; 2- study the stress-strain behavior to failure of all gages; 3- detect and identify splitting damage in all plies, 4- determine all the failure mechanisms involved; 5 -and determine the notch sensitivity of each lay-up.

\section{TEST RESULTS}

\section{Stress-Strain Behavior}

The stress-strain behavior for the $\left[0^{\circ}\right] 8$ specimens and gage arrangement (A) is depicted in Figure (2). Strains measured by gages 3 and 4 demonstrated intensification at the start of loading. Alleviation of the strain concentration, detected by gage 3 , was an indication of split initiation at the hole tip. The plot of this strain component finally coalesced with that of gage 1. Splitting was detected early in the test. The strain measured by gage 4 was 
completely alleviated, or reduced to zero, when the split length grew larger than the hole radius. In other words, splitting rendered the notch bounded region a stress-free one.

Typical stress-strain plots for the $\left[0 / \pm 45^{\circ}\right]_{s}$ specimens and gage arrangement (B) are depicted in Figures $(3,4)$. Both the longitudinal and transverse far-field stress-strain plots are linear to fracture. Strains measured at the hole tip exhibit significant non-linearity accompanied by some perturbation near the end of the test and before failure. They also reflect a strain intensification effect due to the hole. The perturbation in strain at the notch tip was used to make inferences regarding the character of the damage occurring at these sites before final failure of the specimen.

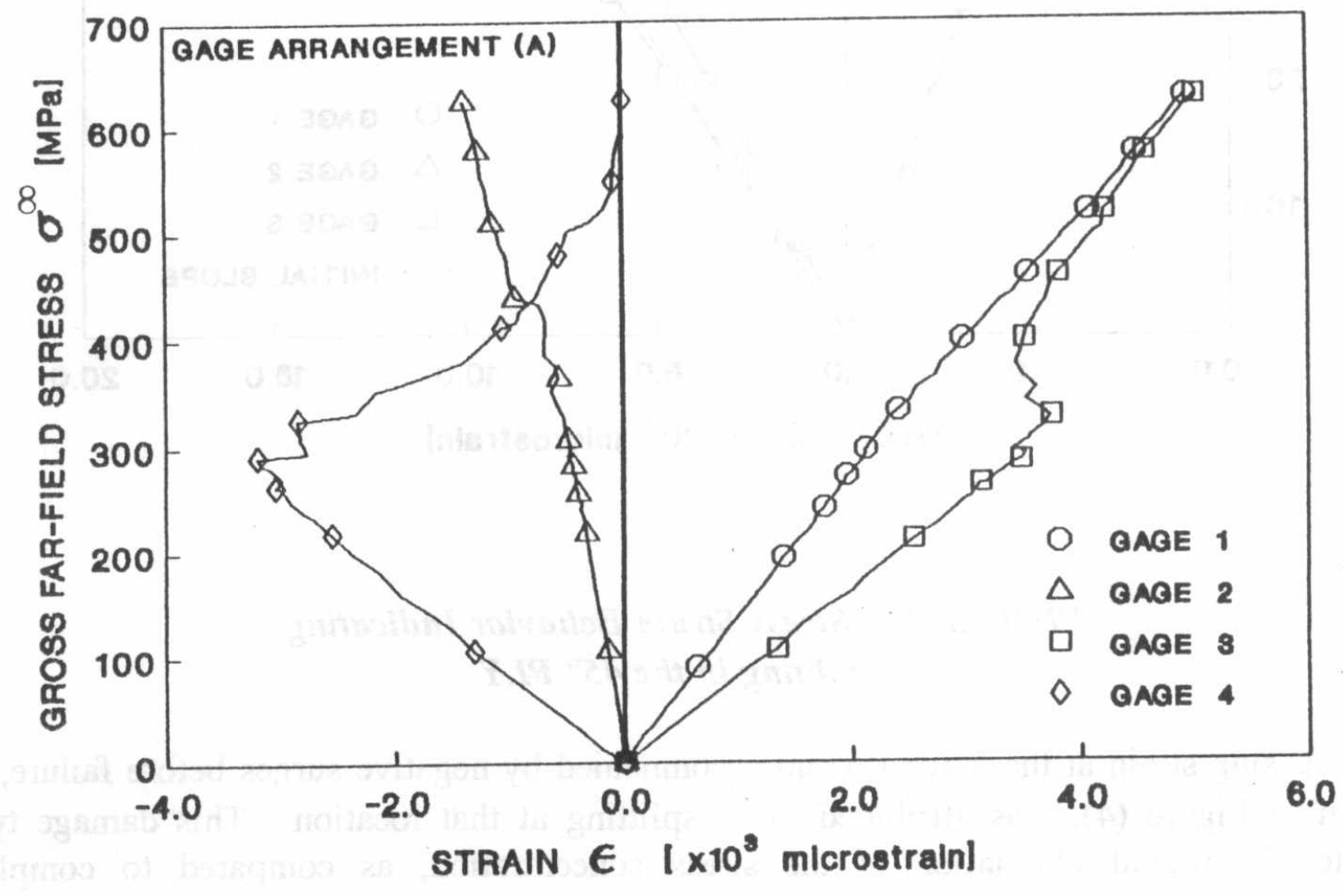

\section{FIGURE (2): Stress-Strain Behavior in Unidirectional Graphite/Epoxy Composites}

Two strain perturbation patterns have been identified. When the notch tip strain increased and exhibited sudden positive jumps before final failure, as shown in Figure (3), this behavior was attributed to matrix splitting in the $\pm 45^{\circ}$ off-axis plies. This damage type resulted in the redistribution of stresses and accordingly raising the magnitude of strain in the $0^{\circ}$ play at this site. The $0^{\circ}$ ply acted as a load bridge to transfer load between the two parts of the $\pm 45^{\circ}$ broken by matrix splits. 


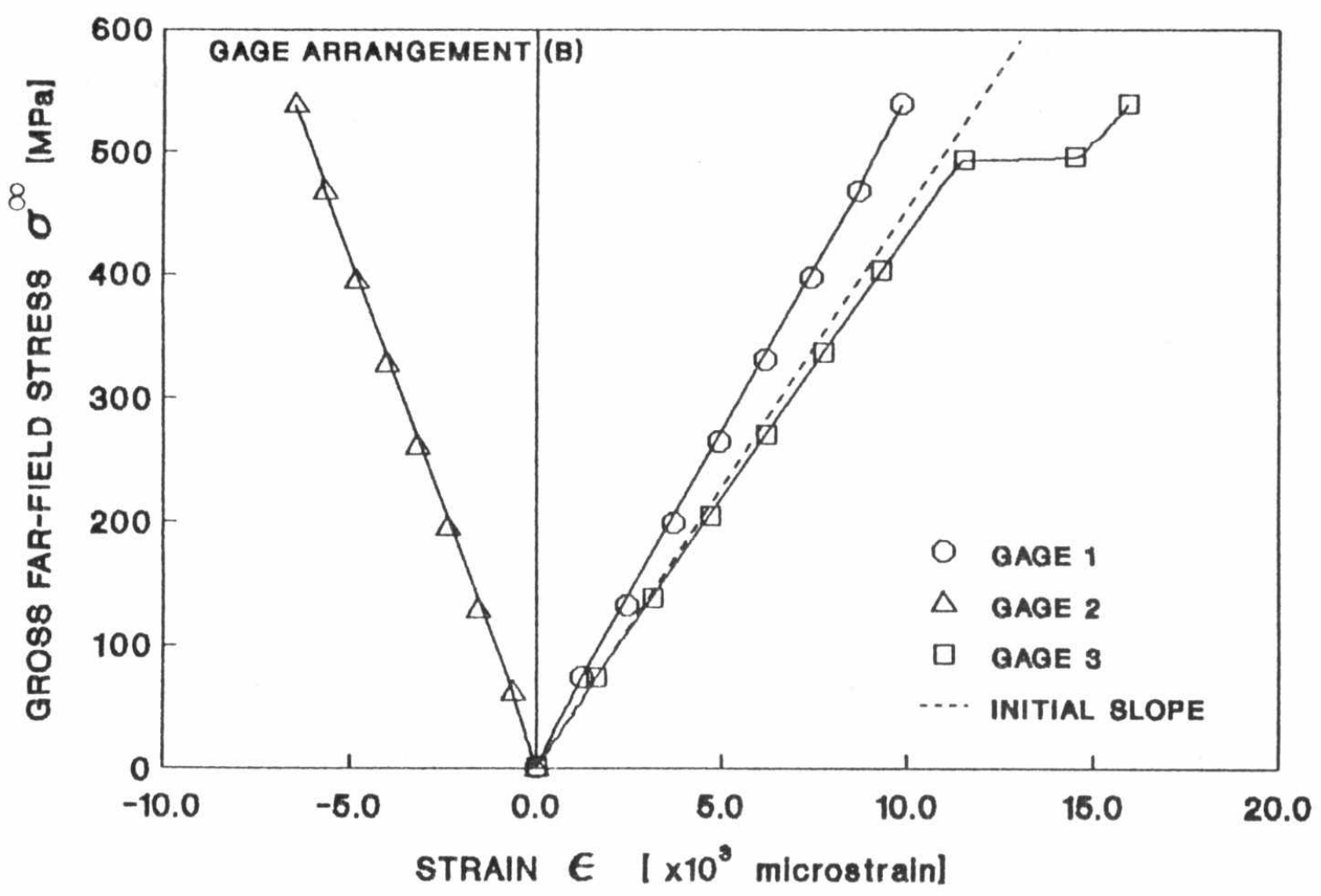

FIGURE (3): Stress-Strain Behavior Indicating Splitting in the $45^{\circ} \mathrm{PLY}$

A decreasing strain at the notch tip and accompanied by negative surges before failure, as shown in Figure (4), was attributed to $0^{\circ}$ splitting at that location. This damage type resulted in partial alleviation of the stress concentration, as compared to complete alleviation in the $\left[0^{\circ}\right] 8$ stacking sequence.

The constraining $\pm 45^{\circ}$ plies limited the free propagation of the $0^{\circ}$ splits. In the unidirectional case, load in the notch bounded region of the specimen is supported by only matrix shear stresses. In the multidirectional case, on the other hand, the load in the notch bounded region is supported by matrix shear as also interlaminar shear stresses in the $0 /+45$ interface.

\section{Failure Modes}

Loading a notched unidirectional composite in tension, along the filament direction, introduce strain concentrations at the notch tips, Figure (5.a). The micro-cracks present at the notch tips are accordingly stressed in mode I loading. As load is increased, these micro- 
cracks bifurcate creating matrix splits. Splits in the $0^{\circ}$ plies are simply mode II microcracks whose further growth is caused by shear stresses in the matrix. These stresses result from the load in the notch bounded region, that tries to pull-out of the specimen.

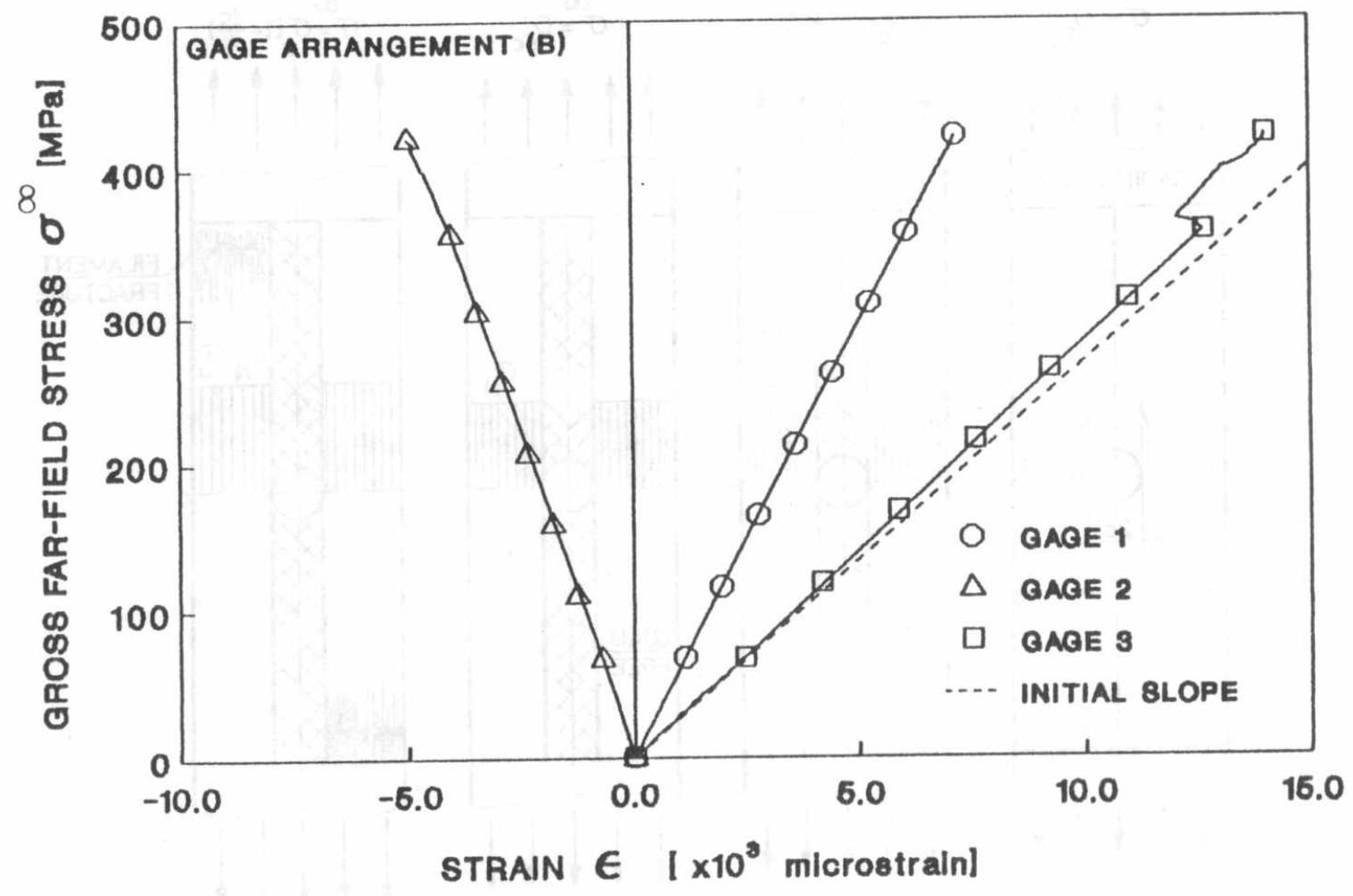

\section{FIGURE (4): Stress-Strain Behavior Indicating $0^{\circ}$ Ply Splitting}

Bifurcation of mode I micro-cracks is due to the relative strength, stiffness, and bond strength of the filament/matrix system. As splitting grows away from the notch tips, strain alleviation occurs producing a uniform stress distribution in the net section, Figure (5.b). Stable splitting growth continues under increasing load until the far-field stress reaches a critical value. At this critical stress unstable splitting growth occurs that physically separates the specimen into three regions. A load-free region at the center, that is bounded by splits, and two outer load-carrying regions. The specimen then behaves as two unnotched strips that ultimately fail due fiber fractures at the material's virgin strength [9].

The fracture mode for all the $\left[0 / \pm 45^{\circ}\right]_{\mathrm{s}}$ specimens is apparently the same. It is characterizes by an un-clean non-self similar fracture surface exhibiting almost all possible basic 
failure modes observed in advanced composites. This includes filament fracture, matrix cracking, delamination, and matrix splitting in axial and off-axis plies. From this damage mode a scenario for the sequence of damage events can be conjectured. Failure starts with multiple splits developing in the off-axis plies in the notch region, as shown in Figure (6).

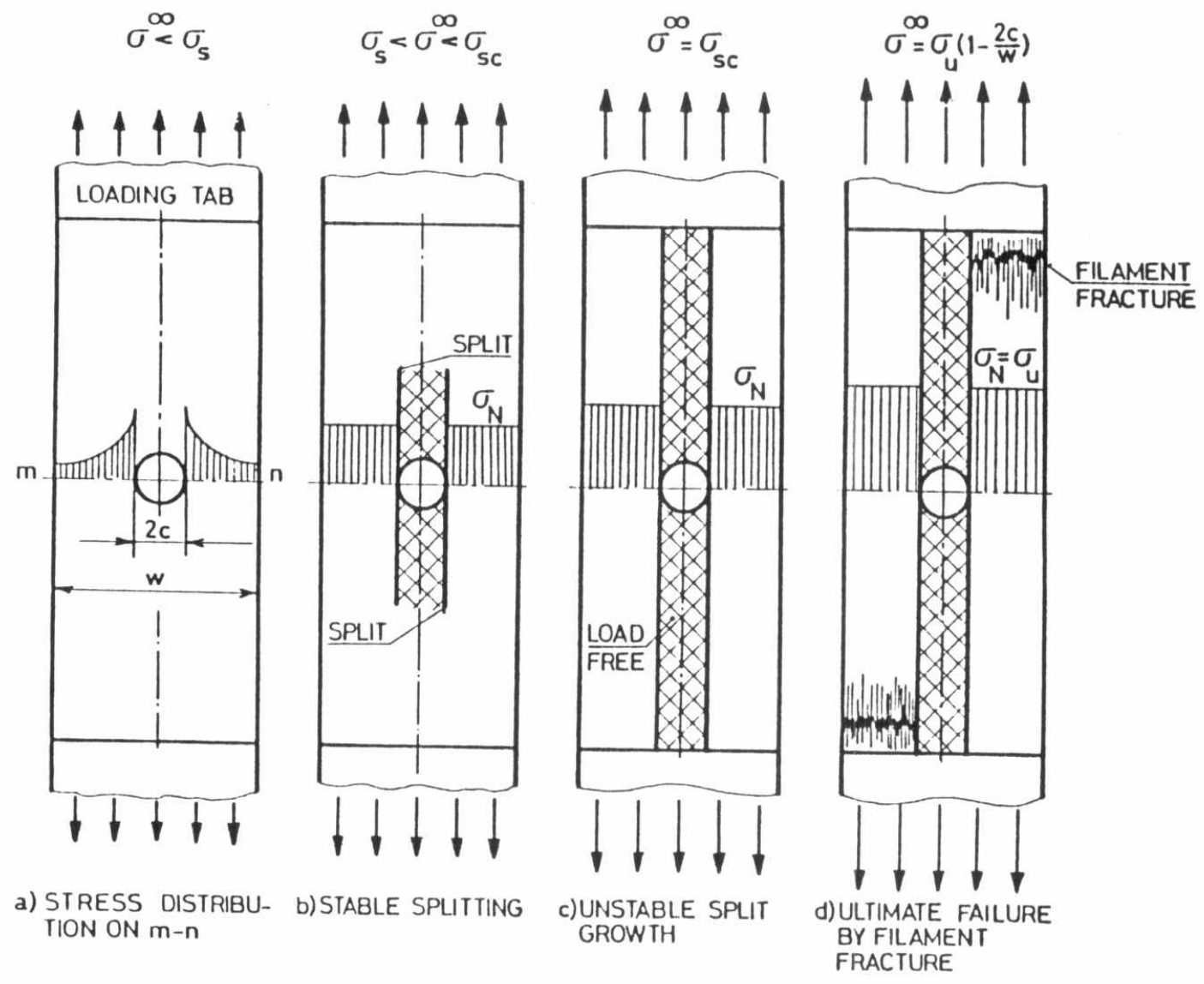

\section{FIGURE (5): Sequence of Dainuge Events in the Unidirectional Specimens}

This damage might sometimes be preceded by limited splitting in the $0^{\circ}$ ply at the notch tips. Formation of the $+45^{\circ}$ matrix splitting increases the stress in the outer $0^{\circ}$ plies and causes them to fail by filament fracture along a jagged plane emanating from the notch tips. This plane makes, in general, a $45^{\circ}$ angle with the load direction. Filament fractures are accompanied by the formation of $0^{\circ}$ ply matrix splits along this $45^{\circ}$ pline. The dynamics of filament fractures trigger delamination at both the $\pm 45^{\circ}$ and $0 / 45^{\circ}$ ply interfaces.

Figure ( 7 ) is a set of post-mortem photographs for both laminate types. Figure (8) is a plot of the tensile strength versus hole size for both laminates. As can be seen, specimens of the unidirectional laminate did not produce any notch sensitivity. 


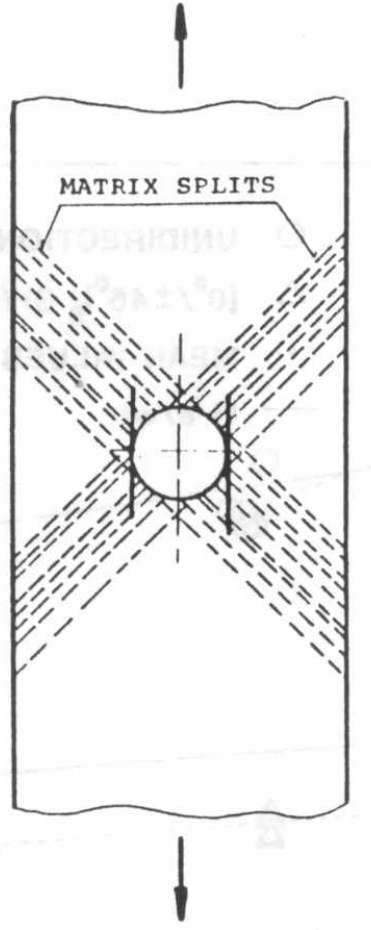

of $\mathrm{f}$-axis ply and $0^{\circ} \mathrm{ply}$ matrix splitting in the notch region
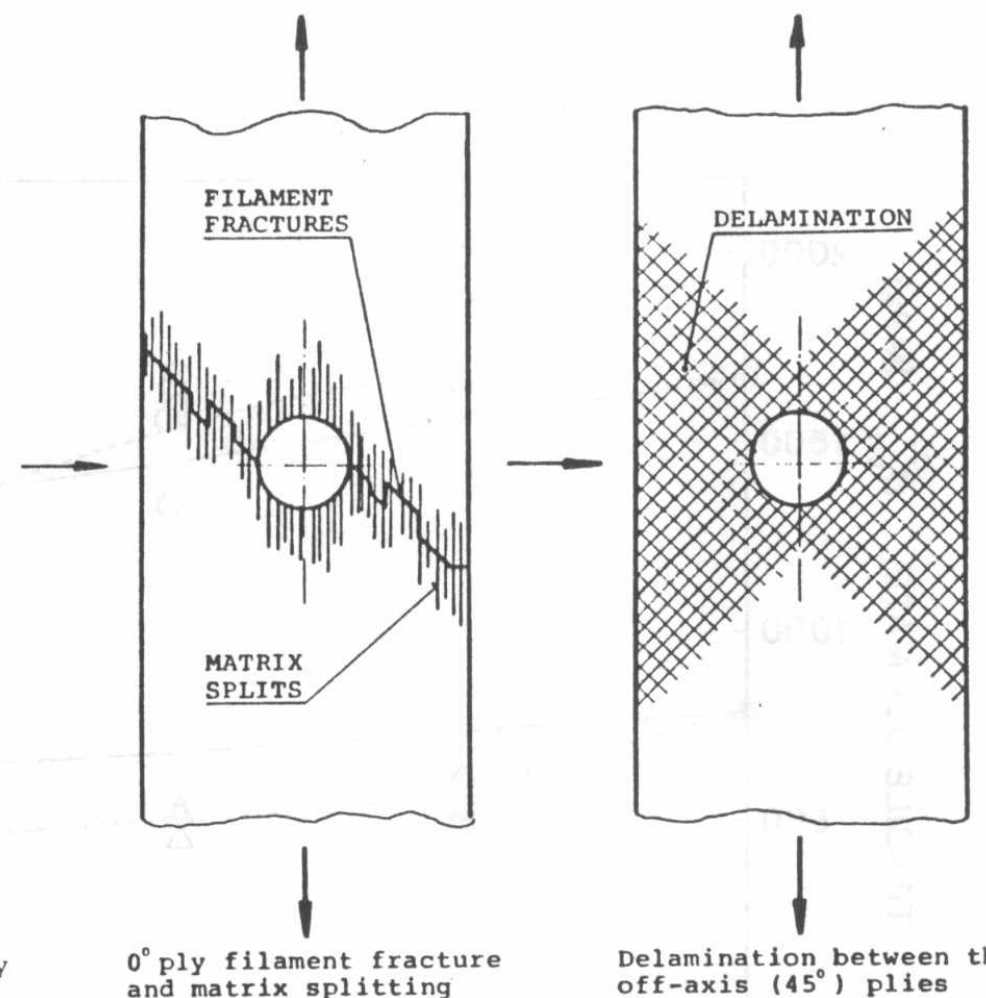

Delamination between the off-axis $\left(45^{\circ}\right)$ plies

FIGURE (6): Sequence of Damage Events in the Multidirectional Specimens
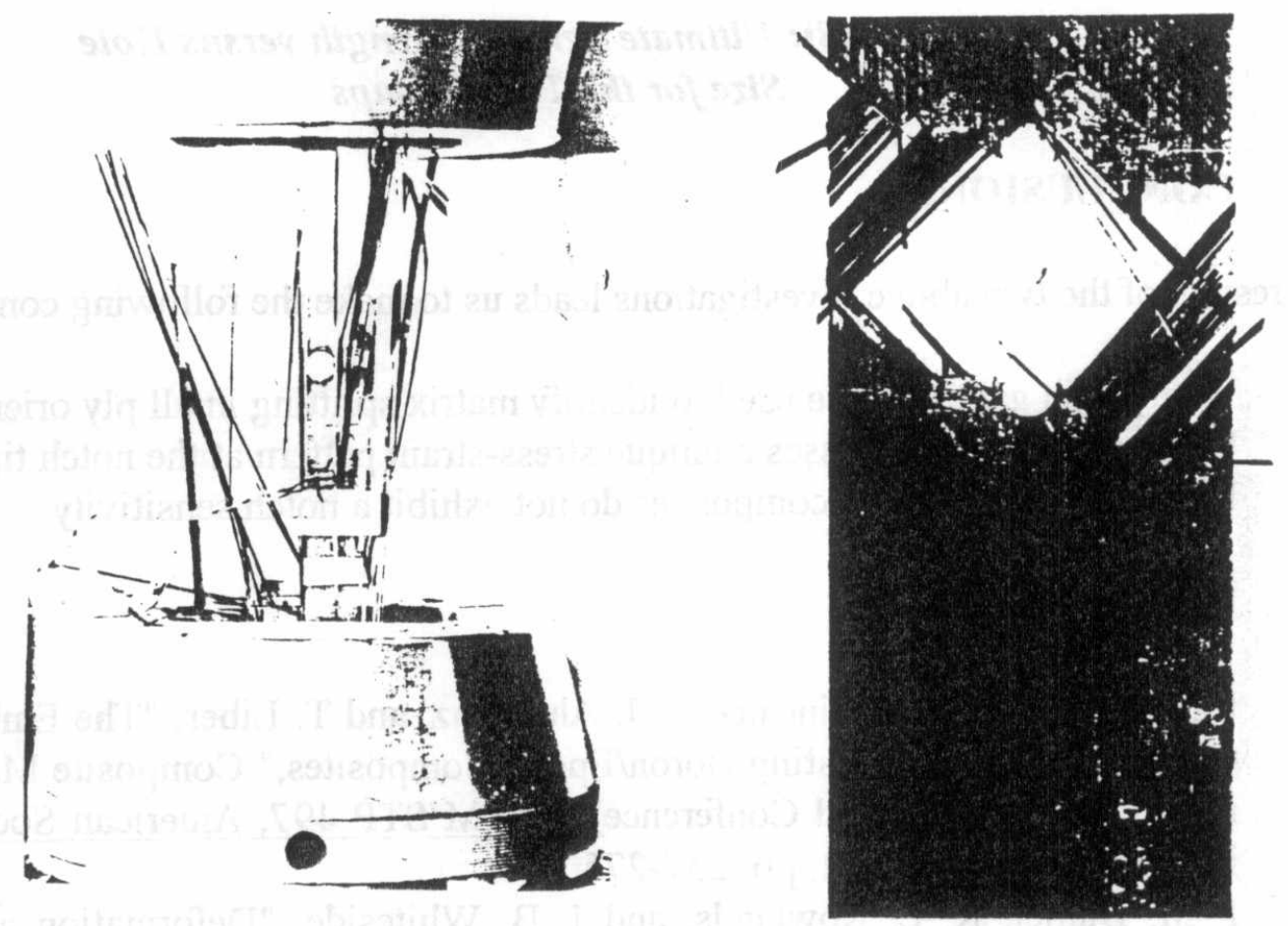

FIGURE (7): Postmortem Photographs for Specimens with the Two Lay-ups 


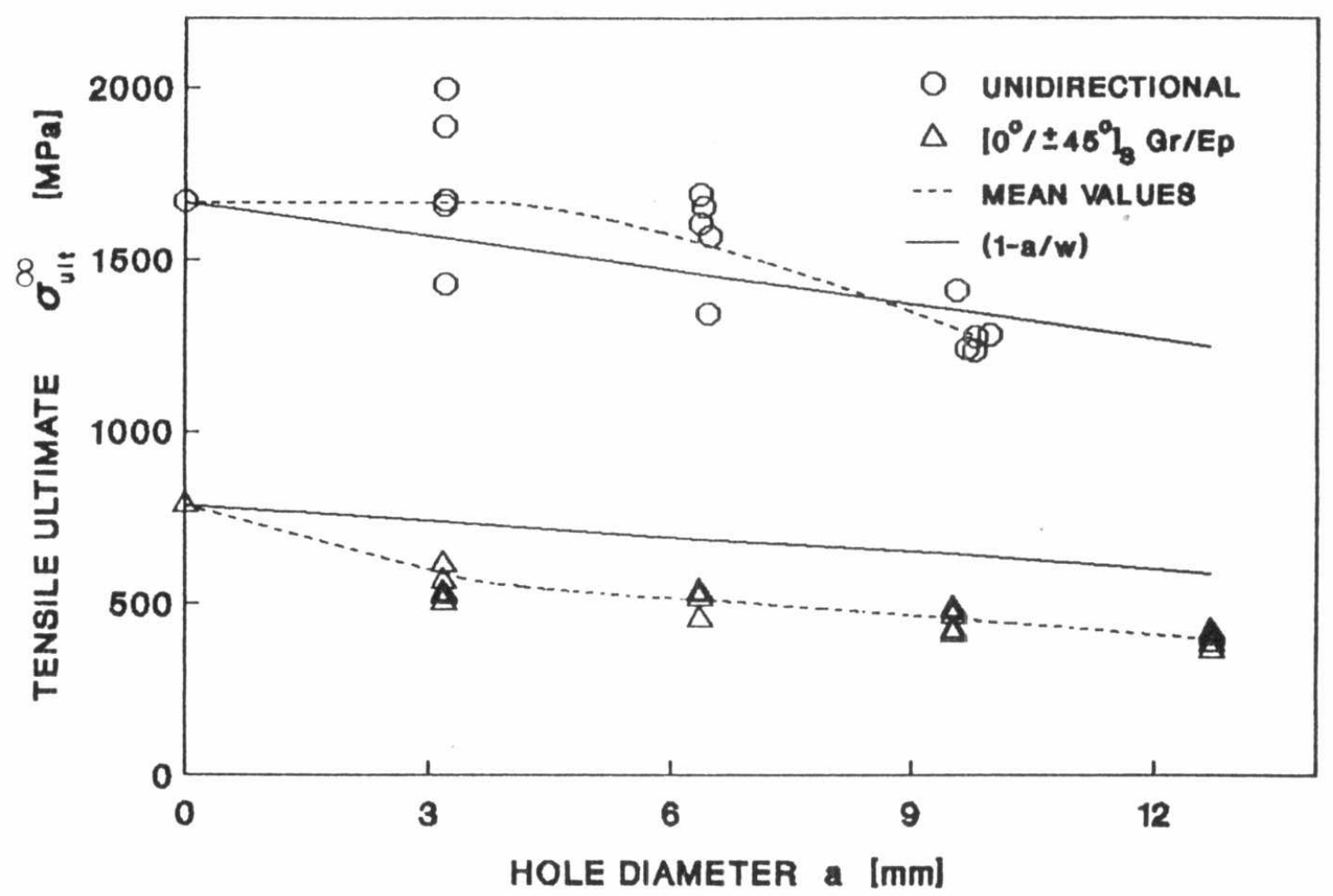

FIGURE (8): Ultimate Tensile Strength versus Hole Size for the Two Lay-ups

\section{CONCLUSIONS}

The results of the two above investigations leads us to make the following conclusions:

1- Wire strain gages can be used to identify matrix splitting in all ply orientations.

2- Unidirectional plies posses a unique stress-strain pattern at the notch tips.

3- Notched unidirectional composites do not exhibit a notch sensitivity.

\section{REFERENCES}

[1] I. M. Daniel, J. I. Mullineaux, F. J. Ahmimaz, and T. Liber, "The Embedded Strain Gage Technique for Testing Boron/Epoxy Composites," Composite Materials: Testing and Design (Second Conference), ASTM STP 497, American Society for Testing and Materials, 1972, pp. 257-275.

[2] I. M. Daniel, R. E. Rowlands, and J. B. Whiteside, "Deformation and Failure of Boron/Epoxy Plate with Circular Hole," Analysis of the Test Methods for High Modulus Fibers and Composites, ASTM STP 521, American Society for Testing and Materials, 1973, pp. 143-164. 
[3] R. B. Pipes, "Interlaminar Shear Fatigue of Fiber reinforced Composite Materials, Composite Materials Testing and Design (Third Conference), ASTM STP 546. American Society for Testing and Materials, 1974, pp. 419-432.

[4] N. M. Bhatia and R. M. Vertte, " Crack Arrestment in Laminated Composites," Fracture Mechanics of Composites, ASTM STP 593, American Society for Testing and Materials, 1975 , pp. 200-214.

[5] J. H. Strands, Jr, M. D. Rhodes, and J. G. Williams, "Effect of Impact Damage and Holes on the compressive Strength of a Graphite/Epoxy Laminate," Non-destructive Evaluation and Flaw Criticality for Composite Materials, ASTM STP 696, American Society for Testing and Materials, 1979, pp. 147-171.

[6] I. M. Daniel, " Biaxial Testing of Graphite/Epoxy Laminates with Cracks," Test Methods and Design Allowables for Fibrous Composites, ASTM STP 734, American Society for Testing and Materials ${ }_{2}$ 1981, pp. 109-128.

[7] P. A. Lagace, "Notch Sensitivily and Stacking Sequence of Laminated Composites," Composite Materials: Testing and Design (Seventh Conference), ASTM STP 893, American Society for Testing and Materials, 1986, pp. 161-176.

[8] Standard Test Method for Tensile Properties of Fiber-resin composites, ASTM D 3039, American Socicty for Testing and Materials, 1988.

[9] H. H. Daken and J. W. Mar, "Splitting Initiation and Propagation in Notched Unidirectional Graphite/Epoxy Composites Under Tension-Tension Cyclic Loading, Composite Structures: An International Journal, December 1985, pp. 111-133. 